\title{
The association of drooling and health-related quality of life in children with cerebral palsy
}

This article was published in the following Dove Press journal:

Neuropsychiatric Disease and Treatment

10 December 2012

Number of times this article has been viewed

\section{Shih-Chung Chang' \\ Chin-Kai Lin ${ }^{2}$ \\ Li-Chen Tung ${ }^{3}$ \\ Nai-Yin Chang'}

'Department of Physical Medicine and Rehabilitation, School of Medicine, Chung Shang Medical University Hospital, Taichung, Taiwan; ${ }^{2}$ Program of Early Intervention, Department of Early Childhood Education, National Taichung University of Education, Taichung, Taiwan; ${ }^{3}$ Department of Physical Medicine and Rehabilitation, Chi Mei Medical Center, Tainan, Taiwan
Correspondence: Chin-Kai Lin I 40 Min-Shen Road, Taichung 40306 Taiwan

Tel +886 422183007

Fax +886422183380

Email linchinkai97@gmail.com
Objective: To investigate the association between drooling in children with cerebral palsy (CP) and their health-related quality of life (HRQOL), as well as the possible variables that predict their HRQOL.

Method: A cross-sectional design was used for this study. Children with CP, without other identified disease, aged 2 to 6 years, who drool $(n=33)$ or did not drool $(n=14)$, were included. The dependent variables were the physical health summary scores and the psychosocial health summary scores of the Pediatric Quality of Life Inventory version 4.0. The $t$ test, Pearson product-moment correlation, Mann-Whitney $U$ test and stepwise regression analysis were used for statistical analysis.

Results: The physical health and psychosocial health summary scores of the children that drooled (16.29 \pm 15.97 and $42.92 \pm 17.57$, respectively) were lower than for the children that did not drool (31.97 \pm 22.22 and 57.09 \pm 12.21 , respectively; $P<0.01)$. The drooling ranking score was negatively correlated with the physical health summary score $(r=-0.355 ; P<0.05)$ and the psychosocial health summary score $(r=-0.381 ; P<0.01)$. The stepwise regression showed that gross motor development and the drooling ranking score predicted $56.6 \%$ of the variability of the physical health summary score $\left(\mathrm{R}^{2}=0.566 ; P<0.01\right)$. The language development score predicted $25.6 \%$ of the variability of the psychosocial health summary score $\left(\mathrm{R}^{2}=0.256 ; P<0.01\right)$.

Conclusion: Drooling was associated with a lower HRQOL. Prediction of the physical health summary score was more closely associated with gross motor development and the drooling ranking scores. Prediction of the psychosocial health summary score was more closely associated with the language development of children with CP aged 2 to 6 years.

Keywords: cerebral palsy, drooling, health-related quality of life

\section{Introduction}

Drooling is common among children with cerebral palsy (CP). The estimated prevalence has been reported from $16.8 \%$ to $58 \% .^{1-5}$ Frequent drooling may cause skin maceration and infection, body fluid loss, and recurrent pneumonia. ${ }^{6,7}$ At school and at home, children with salivary secretions may cause damage to books, teaching materials and furniture, and it even interferes with social relationships. ${ }^{6,8,9}$ van der Burg et al ${ }^{8,10}$ reported that children with $\mathrm{CP}$ that drool are often avoided by other children, and familiar and unfamiliar adults (including their parents). Hockstein et $\mathrm{al}^{9}$ reported that drooling in children with CP could interfere with their education and increase their dependent level of care. Such studies suggest that drooling might be associated with a reduced quality of life among children with $\mathrm{CP}$. 
Previous studies have shown that there are many factors that interfere with the health-related quality of life (HRQOL) in children with CP including: motor, cognitive, language, and social impairment. ${ }^{11-14}$ Although the prevalence of drooling is high among children with $\mathrm{CP}$, there are few articles regarding its relationship to the HRQOL in these children. Most prior studies $^{8,10,15}$ have used modified questionnaires or qualitative methods to evaluate the relationship between drooling and HRQOL. In this study, standardized measurement of the HRQOL in children with CP, with and without drooling, was investigated. In addition, the relationship between drooling and HRQOL was evaluated, as well as the factors that predict the variability of HRQOL in these children.

\section{Materials and methods Participants}

Children with CP that attended one medical center hospital and two early intervention institutions at daytime for an early intervention and habilitation program in Taiwan were enrolled. Children with CP, aged 2 to 6 years, without drooling (with a drooling ranking score of 2 according to the Drooling Rating Scale developed by Thomas-Stonell and Greenberg $^{16}$ ), were the control group. Children with CP, aged 2 to 6 years, with drooling (a drooling ranking score $>2$ ), were the study group. The exclusion criteria were: (1) children with CP combined with other problems such as congenital malformation or metabolic disorder, (2) children taking anticholinergic drugs over the past 2 months, and (3) children with an acute infection or other systemic disease. Children with CP were enrolled consecutively from February 2011 to July 2011. The study was conducted according to the criteria of the Declaration of Helsinki and the review board of the university hospital approved this study. Informed consents were obtained by parents.

Forty-seven children were included in the study: 14 did not drool (mean age: $43.2 \pm 13.8$ months, diplegia $17 \%$, quadriplegia $12.8 \%$ ) and 33 did drool (mean age: $48.9 \pm 14.4$ months, diplegia 10.6\%, quadriplegia 59.6\%). In the group without drooling, there were eight boys and six girls, and in the group with drooling, there were 22 boys and 11 girls (Table 1). Previous studies ${ }^{4,17}$ have reported that drooling in infancy usually resolves by 18 months of age. The children that drool beyond 4 years of age are considered abnormal and require further treatment. Therefore, the participants were divided into groups; those less than 4 years old ( $>2$ years and $<4$ years, as the age group where drooling was supposed to stop and conservative management of drooling was acceptable) and those older than 4 years of age
( $\geq 4$ years, as the age group where drooling was abnormal and required further treatment). Table 1 compares the rate drooling and HRQOL of different age groups.

\section{Outcome measures}

The ranking of drooling was evaluated using the Drooling Rating Scale as described by Thomas-Stonell and Greenberg. ${ }^{16}$ The Drooling Rating Scale was rated using two subscales: (1) drooling severity with a scale from 1 to 5 , where $1=$ never drools, $2=$ mild drooling causing wet lips only, 3 = moderate drooling causing wet lips and chin, $4=$ severe drooling where clothing becomes damp, and 5 = profuse drooling causing clothing, hands, and the subjects in general to get wet; (2) drooling frequency with a scale from 1 to 4 , where $1=$ never drools, $2=$ occasionally drools, $3=$ frequently drools, and $4=$ constantly drools. The drooling ranking score was determined by adding the two subscales together (drooling severity + drooling frequency). The drooling ranking score was rated from 2 to 9 , with a ranking score of 2 representing no drooling and a ranking score of 9 as the most severe level of drooling. The parents or the children's primary caregivers rated the drooling, at least 1 hour before or after meals.

The HRQOL of these children was rated using the Pediatric Quality of Life Inventory Version 4.0 (PedsQL 4.0) for toddlers (ages 2-4) and young children (ages 5-7) using the generic core scales, which combined four subscales that included: (1) Physical Functioning, (2) Emotional Functioning, (3) Social Functioning, and (4) School Functioning. The scoring dimensions included: (1) a physical health summary score that represented

Table I Demographic characteristics of children with cerebral palsy (CP)

\begin{tabular}{|c|c|c|c|}
\hline & $\begin{array}{l}\text { Drooling (+) } \\
\text { no }\end{array}$ & $\begin{array}{l}\text { Drooling (-) } \\
\text { no }\end{array}$ & Statistic \\
\hline Sex & & & $\phi=-0.091$ \\
\hline Boy & 22 & 8 & \\
\hline Girl & 11 & 6 & \\
\hline Age & & & $\phi=-0.042$ \\
\hline$<4$ years & I5 (26-46 months) & 7 (24-4I months) & \\
\hline$\geq 4$ years & |8 (48-7| months) & 7 (49-66 months) & \\
\hline Type of CP (no) & & & $\phi=-0.429^{\mathrm{a}}$ \\
\hline Diplegia & 5 & 8 & \\
\hline Quadriplegia & 28 & 6 & \\
\hline \multicolumn{4}{|c|}{ Developmental status (month) } \\
\hline Language & $19.64 \pm 17.90$ & $42.36 \pm 13.45$ & $Z=-3.73^{a}$ \\
\hline Gross motor & $12.88 \pm 12.54$ & $16.36 \pm 13.16$ & $Z=-1.18$ \\
\hline Cognition & $19.76 \pm 17.88$ & $43.36 \pm 17.76$ & $Z=-3.58^{\mathrm{a}}$ \\
\hline
\end{tabular}

Notes: Drooling (+): children with drooling; Drooling (-): children without drooling; $\phi$ : Chi square $\phi ; Z, Z$ score of Mann-Whitney $U$ test; ${ }^{a} p<0.01$. 
a physical functioning scale score, and (2) a psychosocial health summary score that was the sum of the items over the number of items answered in the Emotional, Social, and School Functioning Scales. Parents or the primary caregivers rated the PedsQL 4.0 scores (internal consistency reliability: total scale score Cronbach's $\alpha=0.9$ for parents/ proxy; physical health summary score Cronbach's $\alpha=0.88$ for parents/proxy; psychosocial health summary score Cronbach's $\alpha=0.86$ for parents/proxy). ${ }^{18}$

The developmental status of the children was evaluated using the Developmental Screening Test for 0-6-Year-Old Children (Chinese version, content validity 0.89-0.93), ${ }^{19}$ which was also rated by the parents or primary caregivers. This test evaluated five developmental domains (language, social-personality, gross motor, fine motor, and cognition); the highest scores achieved for each domain were considered the developmental levels. The screening test was correlated with the Bayley Scales of Infant Development I (criterionrelated validity $r=0.229 \sim 0.566 ; P<0.05) .{ }^{19}$

\section{Data analysis}

The mean differences in HRQOL scores among the two groups were analyzed with the Mann-Whitney $U$ test. The correlation of the drooling ranking score, the developmental status, and the HRQOL was analyzed with the Pearson product-moment correlation coefficient. Stepwise regression analysis was used for the prediction of variability of the HRQOL. Statistical analyses were performed using SPSS software (v 12.0; IBM, Armonk, NY). The significance level was set at $P<0.05$.

\section{Results}

There were no significant correlations with sex and age of those that drooled compared to those that did not drool (Table 1). However, the diagnosis of diplegia or quadriplegia was associated with a significant difference; there were more children with quadriplegia that drooled and fewer with diplegia that drooled $(P<0.01$, Table 1$)$. Table 1 also shows a comparison of the developmental status between those that drooled and those that did not drool. The language developmental status (in months) of the children that drooled was significantly lower compared to the children that did not drool (19.64 \pm 17.90 vs $42.36 \pm 13.45 ; P<0.01)$. The cognitive developmental status of the children that drooled was lower than in the children that did not drool $(19.76 \pm 17.88$ vs $43.36 \pm 17.76 ; P<0.01)$. There was no significant difference in the gross motor developmental status between the children that drooled and those that did not drool $(12.88 \pm 12.54$ vs $16.36 \pm 13.16 ; P>0.05)$.
There were no significant differences in the HRQOL (physical health summary score and psychosocial health summary score) by sex (18.96 \pm 17.43 vs $24.49 \pm 22.16$, $t=-0.95, P>0.05$ and $49.20 \pm 16.68$ vs $43.51 \pm 18.31$, $t=1.09, P>0.05$, respectively; Table 2$)$ and by age group $(25.57 \pm 19.66$ vs $16.90 \pm 28.25, t=1.57, P>0.05$ and $52.13 \pm 16.43$ vs $42.75 \pm 17.19, t=1.91, P>0.05$, respectively). The physical health summary scores of the quadriplegic group were significantly lower than those of the diplegic group $(34.19 \pm 18.69$ vs $15.90 \pm 17.11, t=3.20$, $P<0.01$ ); however, there were no significant differences observed on the psychosocial health summary scores $(53.48 \pm 10.70$ vs $44.72 \pm 18.82, t=1.58, P>0.05)$. For the children that drooled, both the physical health summary scores and the psychosocial health summary scores were significantly lower than the scores for the children that did not drool $(31.97 \pm 22.22$ vs $16.29 \pm 15.97, t=2.73, P<0.01$ and $57.09 \pm 12.21$ vs $42.92 \pm 17.57, t=2.74, P<0.01$, respectively).

In order to determine which variables (developmental status and drooling ranking scales) could be enrolled in stepwise regression to predict the variability of HRQOL, correlations between the variables and the HRQOL were studied first (Table 3 ). Those predictor variables which were significant correlated with HRQOL were enrolled in the stepwise regression study. The drooling ranking score was negatively correlated with the physical health summary score $(r=-0.355 ; P<0.05)$ and psychosocial health summary score $(r=-0.381 ; P<0.01)$. The developmental status (language, gross motor, and cognition) of the children was

Table 2 Comparison of sex, age, type of CP, and drooling with the HRQOL

\begin{tabular}{|c|c|c|c|c|}
\hline & \multicolumn{2}{|c|}{$\begin{array}{l}\text { Physical summary } \\
\text { score }\end{array}$} & \multicolumn{2}{|c|}{$\begin{array}{l}\text { Psychosocial } \\
\text { summary score }\end{array}$} \\
\hline & Mean \pm SD & $t$ & Mean \pm SD & $t$ \\
\hline \multicolumn{5}{|l|}{ Sex } \\
\hline Boy & $18.96 \pm 17.43$ & -0.95 & $49.20 \pm 16.68$ & 1.09 \\
\hline Girl & $24.49 \pm 22.16$ & & $43.51 \pm|8.3|$ & \\
\hline \multicolumn{5}{|l|}{ Age } \\
\hline$<4$ years & $25.57 \pm 19.66$ & 1.57 & $52.13 \pm 16.43$ & 1.91 \\
\hline$\geq 4$ years & $16.90 \pm 28.25$ & & $42.75 \pm 17.19$ & \\
\hline \multicolumn{5}{|l|}{ Type of CP } \\
\hline Diplegia & $34.19 \pm 18.69$ & $3.20^{\mathrm{a}}$ & $53.48 \pm 10.70$ & 1.58 \\
\hline Quadriplegia & $15.90 \pm|7.1|$ & & $44.72 \pm 18.82$ & \\
\hline \multicolumn{5}{|l|}{ Drooling } \\
\hline Drooling (-) & $31.97 \pm 22.22$ & $2.73^{\mathrm{a}}$ & $57.09 \pm 12.21$ & $2.74^{\mathrm{a}}$ \\
\hline Drooling (+) & $16.29 \pm 15.97$ & & $42.92 \pm 17.57$ & \\
\hline
\end{tabular}

Notes: Statistics with the $t$ test; ${ }^{a}<<0.01$.

Abbreviations: CP, cerebral palsy; HRQOL, health-related quality of life; SD, standard deviation. 
Table 3 Correlations between drooling ranking, developmental status, and HRQOL

\begin{tabular}{llllll}
\hline & $\begin{array}{l}\text { Physical } \\
\text { health } \\
\text { summary } \\
(\boldsymbol{r})\end{array}$ & $\begin{array}{l}\text { Psychosocial } \\
\text { health }\end{array}$ & $\begin{array}{l}\text { Drooling } \\
\text { summary } \\
\text { ranking } \\
(\boldsymbol{r})\end{array}$ & $\begin{array}{l}\text { Language } \\
(\boldsymbol{r})\end{array}$ & $\begin{array}{l}\text { Gross } \\
\text { motor } \\
(\boldsymbol{r})\end{array}$ \\
\hline $\begin{array}{l}\text { Drooling } \\
\text { ranking }\end{array}$ & $-0.355^{\mathrm{a}}$ & $-0.38 \mathrm{I}^{\mathrm{b}}$ & & & \\
Language & $0.477^{\mathrm{b}}$ & $0.522^{\mathrm{b}}$ & $-0.589^{\mathrm{b}}$ & & \\
$\begin{array}{l}\text { Gross } \\
\text { motor }\end{array}$ & $0.716^{\mathrm{b}}$ & $0.383^{\mathrm{b}}$ & -0.123 & $0.458^{\mathrm{b}}$ & \\
Cognition & $0.503^{\mathrm{b}}$ & $0.516^{\mathrm{b}}$ & $-0.537^{\mathrm{b}}$ & $0.900^{\mathrm{b}}$ & $0.501^{\mathrm{b}}$ \\
\hline
\end{tabular}

Notes: $r$, Pearson correlation coefficient; a $P<0.05$; ${ }^{b} P<0.01$.

Abbreviation: $\mathrm{HRQOL}$, health-related quality of life.

positively correlated with both the physical health summary score $(r=0.477,0.716$, and 0.503 , respectively; $P<0.01)$ and the psychosocial health summary score $(r=0.522,0.383$, and 0.516 , respectively, $P<0.01$ ). Thus the drooling ranking score and the developmental status of language, gross motor, and cognition factors were included in the stepwise regression analysis because they were significantly correlated with HRQOL. The results of the stepwise regression are shown in Table 4. For variability of the physical health summary score, the developmental level of language and cognition was excluded after the stepwise regression (due to $P>0.1$ ). The drooling ranking score and gross motor development predicted $56.6 \%$ of the variation of the physical health summary score $\left(\mathrm{R}^{2}=0.566 ; P<0.01\right)$. For the prediction of variability of the psychosocial health summary score, the drooling ranking score, gross motor development, and cognitive development scores were excluded after stepwise regression (due to $P>0.1$ ). The language development level predicted $25.6 \%$ of the variation of the psychosocial health summary score $\left(\mathrm{R}^{2}=0.256 ; P<0.01\right)$.

\section{Discussion}

The frequency of drooling in the quadriplegic children was greater than in the diplegic children. This result is compatible with the findings of Hegde and Pani ${ }^{3}$ that showed that patients with quadriplegia had the most severe drooling, followed by children with diplegia and the least affected children had athetoid CP. But other reports showed opposite results and they found the drooling is more prevalent and intense in children with dyskinetic $\mathrm{CP}$ than in children with spastic CP. ${ }^{5,20}$ The main etiologies of drooling include: impaired postural control as well as oral-motor and swallowing abnormalities. ${ }^{3,20-22}$ The quadriplegic children with $\mathrm{CP}$ are more likely to develop drooling due to their more extensive brain dysfunction and poor oral motor and sensory function compared to the diplegic children with CP. In this paper, there was no dyskinetic-type $\mathrm{CP}$ enrolled for study so we cannot compare the drooling problem with other CP subtypes.

The results of this study showed that the language and cognitive development of the children that drooled was lower than in the children that did not drool; however, the gross motor development showed no significant difference between these two groups (Table 1). These findings are compatible with the report of Senner et $\mathrm{al}^{23}$ that showed that children who drooled had more severe dysarthria and impaired nonverbal intelligence, but their gross motor status was not more impaired; although impaired motor control was considered one of the contributing factors of drooling..$^{21,22}$

Children at different developmental stages may have different findings and explanations for their disease. ${ }^{24,25}$ Younger children were less likely to be perceived as performing less well on the HRQOL questions than older children. ${ }^{26}$ It is possible that finding no significant HRQOL differences between age groups, in this study, was due to the younger ages of our study groups. Previous studies ${ }^{12,14}$ also revealed that the HRQOL (both physical and psychosocial) of quadriplegic children was lower than that of diplegic children. In this study, the physical health summary scores of quadriplegic children were lower than diplegic children; however, the psychosocial health summary score was not. The possible explanations for this result include: (1) most of the subjects attended early intervention institutions or a hospital program, where they possibly had a more supported and structured environment and received less negative feedback from social interaction; ${ }^{10,14}(2)$ most of the subjects were young and

Table 4 Stepwise regression of drooling ranking and developmental status

\begin{tabular}{|c|c|c|c|c|c|c|c|c|}
\hline & \multicolumn{4}{|c|}{ Physical health summary score } & \multicolumn{4}{|c|}{ Psychosocial health summary score } \\
\hline & $\beta$ & $\boldsymbol{t}$ & $\boldsymbol{P}$ & Tolerance & $\beta$ & $t$ & $\boldsymbol{P}$ & Tolerance \\
\hline Drooling ranking & -0.271 & -2.772 & $<0.01$ & & $(-)$ & & & 0.653 \\
\hline Language & $(-)$ & & & 0.501 & 0.522 & 4.103 & $<0.01$ & \\
\hline Gross motor & 0.683 & 6.977 & $<0.01$ & & $(-)$ & & & 0.790 \\
\hline Cognition & $(-)$ & & & 0.519 & $(-)$ & & & 0.191 \\
\hline
\end{tabular}

Note: (-): excluded in stepwise regression. 
cognitively impaired; the impairment was known since birth and they received support from their caregivers to accomplish daily activities, and therefore had fewer experiences of negative psychosocial well-being; ${ }^{11,27}$ (3) the number of subjects was too small to show a statistically significant difference in psychosocial health scores.

The results of this study showed that the physical health summary scores and psychosocial health summary scores were significantly lower in the children with $\mathrm{CP}$ that drooled than in the children with $\mathrm{CP}$ that did not drool. These results were compatible with previous studies showing that drooling may lead to health-related problems such as skin maceration, recurrent pneumonia, and malnutrition. ${ }^{7,28}$ Although our result showed a significant level of correlation between drooling and psychosocial HRQOL, but the correlation coefficient showed only a lower level of correlation $(r=-0.381 ; P<0.01)$. Some studies have reported that drooling was associated with impaired social relationships of these children with adults and their peers; however, few showed negative emotional reactions due to drooling. ${ }^{8,10,15}$ van der Burg et al ${ }^{10}$ reported that children with $\mathrm{CP}$ who drooled showed few negative emotional reactions because they attended special education schools and the drooling problem seems to be acceptable and ignored in these places.

Although the language and cognitive developmental status was positively correlated with the physical health summary score, these two variables were excluded from the stepwise regression model because of the statistical result of $P \geq 0.1$. Thus, the most important variables left in the stepwise regression model were gross motor development and rank of drooling, and they predicted $56.6 \%$ of the variation of the physical health summary score. In predicting the variation associated with the psychosocial health summary score, the level of drooling, gross motor development and cognitive development were excluded from the stepwise regression model ( $P \geq 0.1$ ); the remaining language development predicted $25.6 \%$ of the variation of the psychosocial health summary score. Dickinson et a $\mathrm{l}^{11}$ showed that gross motor development correlated most with the physical wellness of children with $\mathrm{CP}$; intellectual disability and language impairment significantly interfered with psychosocial wellness. However, drooling was not investigated as a problem that interfered with the quality of life in this prior study. In our study, only the ranking of drooling/gross motor development and language development were considered as important factors associated with the physical health summary score and psychosocial health summary score. There are likely other factors involved that were not evaluated in this study.
Further investigation of these possible variables (eg, family or institutional factors, Gross Motor Function Classification System of children with $\mathrm{CP}$ ) that might be correlated with the HRQOL of children with $\mathrm{CP}$ requires further research.

Although cognitive development was excluded in the stepwise regression model, its importance cannot be overlooked due to nearly the same correlation coefficient associated with the psychosocial health summary score as with the language development score. However, the excluded variables did not add much to predicting the variability of the psychosocial health summary score, when it was included.

Because the subjects in this study were too young or too cognitively impaired, a parent/proxy report was used to assess the drooling and HRQOL of the enrolled children. A bias might have been introduced by parents that were bothered by their children's drooling and inclined to rate their children's HRQOL lower. As in the study by Davis et $\mathrm{al},{ }^{29}$ there was discordance between parent/proxy and child selfreport because they responded to the HRQOL questionnaire items differently. But in this study, the definitions of drooling severity and frequency were clearly defined for parents and primary caregivers. In addition, the standard HRQOL questionnaires were used for the HRQOL evaluation, and were not likely significantly affected by bias. Although a selfreported HRQOL is standard for the perceived HRQOL, the parents are valuable proxies to assess their children's HRQOL if the children are too young or too cognitively impaired to complete a self-reported HRQOL. ${ }^{10,30}$ Therefore, the findings of this study based on parent/proxy reports showed that children with $\mathrm{CP}$ that drooled had a lower HRQOL are important.

\section{Study limitations}

This was a cross-sectional study and focused only on 2- to 6-year-old children with diplegic and quadriplegic CP from a university hospital and early intervention institutions. Because our subjects in this paper were young and recruited from localized areas in Taiwan, and contained only two CP subtypes, the results cannot be generalized to all ages and all groups of children with $\mathrm{CP}$.

\section{Conclusion}

In conclusion, the standard assessment inventory was used to evaluate the correlation of drooling on the HRQOL of children with CP. The more severe the drooling was (without considering the type of $\mathrm{CP}$ ), the lower the physical and psychosocial health quality of life was in the children with CP. The gross motor development level and ranking of drooling predicted the 
physical health score better, and the language development level predicted the psychosocial health score better. With regard to providing early intervention programs for children with CP, their developmental status should be assessed as well as their drooling problem, which has a negative correlation on their HRQOL. The focus of this study was on young children with $\mathrm{CP}$; further evaluation is needed to determine similar correlations among older children with CP.

\section{Disclosure}

No commercial party having a direct financial interest in the results of the research supporting this article has or will confer a benefit upon the authors or upon any organization with which the authors are associated.

\section{References}

1. Santos M, Ferreira M, Leite M, Guaré R. Salivary parameters in Brazilian individuals with cerebral palsy who drool. Child Care Health Dev. 2011;37(3):404-409.

2. Rekha M, Gladstone M, Hanumanthiah H, Giri P, Bassi Z. Children with cerebral palsy and drooling-their clinical profile and management. Arch Dis Child. 2011;96(Suppl 1):A42-A42.

3. Hegde AM, Pani SC. Drooling of saliva in children with cerebral palsy-etiology, prevalence, and relationship to salivary flow rate in an Indian population. Spec Care Dentist. 2009;29(4):163-168.

4. Morales Chavez MC, Nualart Grollmus ZC, Silvestre-Donat FJ. Clinical prevalence of drooling in infant cerebral palsy. Med Oral Patol Oral Cir Bucal. 2008;13(1):E22-E26.

5. Reid SM, McCutcheon J, Reddihough DS, Johnson H. Prevalence and predictors of drooling in 7- to 14-year-old children with cerebral palsy: a population study. Dev Med Child Neurol. 2012;54(11):1032-1036.

6. Crysdale WS, McCann C, Roske L, Joseph M, Semenuk D, Chait P. Saliva control issues in the neurologically challenged. A 30 year experience in team management. Int $J$ Pediatr Otorhinolaryngol. 2006;70(3):519-527.

7. Hussein I, Kershaw AE, Tahmassebi JF, Fayle SA. The management of drooling in children and patients with mental and physical disabilities: a literature review. Int J Paediatr Dent. 1998;8(1):3-11.

8. van der Burg JJ, Jongerius PH, van Limbeek J, van Hulst K, Rotteveel JJ. Social interaction and self-esteem of children with cerebral palsy after treatment for severe drooling. Eur J Pediatr. 2006;165(1):37-41.

9. Hockstein NG, Samadi DS, Gendron K, Handler SD. Sialorrhea: a management challenge. Am Fam Physician. 2004;69(11):2628-2634.

10. van der Burg JJ, Jongerius PH, van Limbeek J, van Hulst K, Rotteveel JJ. Drooling in children with cerebral palsy: a qualitative method to evaluate parental perceptions of its impact on daily life, social interaction, and self-esteem. Int J Rehabil Res. 2006;29(2):179-182.

11. Dickinson H, Parkinson K, Ravens-Sieberer U, et al. Self-reported quality of life of 8-12-year-old children with cerebral palsy: a cross-sectional European study. Lancet. 2007;369(9580):2171-2178.
12. Varni JW, Burwinkle TM, Sherman SA, et al. Health-related quality of life of children and adolescents with cerebral palsy: hearing the voices of the children. Dev Med Child Neurol. 2005;47(9):592-597.

13. Houlihan CM, O’Donnell M, Conaway M, Stevenson RD. Bodily pain and health-related quality of life in children with cerebral palsy. Dev Med Child Neurol. 2004;46(5):305-310.

14. Bjornson KF, McLaughlin JF. The measurement of health-related quality of life (HRQL) in children with cerebral palsy. Eur J Neurol. 2001;8:183-193.

15. van der Burg JJ, Jongerius PH, van Hulst K, van Limbeek J, Rotteveel JJ. Drooling in children with cerebral palsy: effect of salivary flow reduction on daily life and care. Dev Med Child Neurol. 2006;48(2):103-107.

16. Thomas-Stonell N, Greenberg J. Three treatment approaches and clinical factors in the reduction of drooling. Dysphagia. 1988;3(2):73-78.

17. Meningaud JP, Pitak-Arnnop P, Chikhani L, Bertrand JC. Drooling of saliva: a review of the etiology and management options. Oral Surg Oral Med Oral Pathol Oral Radiol Endod. 2006;101(1):48-57.

18. Varni JW, Seid M, Kurtin PS. PedsQL (TM) 4.0: Reliability and validity of the pediatric quality of life Inventory (TM) Version 4.0 generic core scales in healthy and patient populations. Med Care. 2001;39(8): 800-812.

19. Huang H-L. Developmental Screening Test for 0-6-Year-Old Children: User's Manual. Taipei, Taiwan: Psychological Corporation; 2000.

20. Erasmus CE, Van Hulst K, Rotteveel LJ, et al. Drooling in cerebral palsy: hypersalivation or dysfunctional oral motor control? Dev Med Child Neurol. 2009;51(6):454-459.

21. O’Dwyer TP, Timon C, Walsh MA. Surgical management of drooling in the neurologically damaged child. J Laryngol Otol. 1989;103(8): $750-752$.

22. Sochaniwskyj AE, Koheil RM, Bablich K, Milner M, Kenny DJ. Oral motor functioning, frequency of swallowing and drooling in normal children and in children with cerebral palsy. Arch Phys Med Rehabil. 1986;67(12):866-874.

23. Senner JE, Logemann J, Zecker S, Gaebler-Spira D. Drooling, saliva production, and swallowing in cerebral palsy. Dev Med Child Neurol. 2004;46(12):801-806.

24. Eiser C, Morse R. A review of measures of quality of life for children with chronic illness. Arch Dis Child. 2001;84(3):205.

25. Eiser C, Mohay H, Morse R. The measurement of quality of life in young children. Child Care Health Dev. 2000;26(5):401-414.

26. Liu W-Y, Hou Y-J, Wong AM, et al. Health-related quality of life in the pre-school children with cerebral palsy. Formosan J Phys Ther. 2009;34(4):235-243.

27. Shelly A, Davis E, Waters E, et al. The relationship between quality of life and functioning for children with cerebral palsy. Dev Med Child Neurol. 2008;50(3):199-203.

28. Blasco PA, Allaire JH. Drooling in the developmentally disabled: management practices and recommendations. Consortium on Drooling. Dev Med Child Neurol. 1992;34(10):849-862.

29. Davis E, Nicolas C, Waters E, et al. Parent-proxy and child self-reported health-related quality of life: using qualitative methods to explain the discordance. Qual Life Res. 2007;16(5):863-871.

30. Varni JW, Limbers CA, Burwinkle TM. Parent proxy-report of their children's health-related quality of life: an analysis of 13, 878 parents' reliability and validity across age subgroups using the PedsQL(tm) 4. 0 Generic Core Scales. Health Qual Life Outcomes. 2007;5(1):2.

\section{Publish your work in this journal}

Neuropsychiatric Disease and Treatment is an international, peerreviewed journal of clinical therapeutics and pharmacology focusing on concise rapid reporting of clinical or pre-clinical studies on a range of neuropsychiatric and neurological disorders. This journal is indexed on PubMed Central, the 'PsycINFO' database and CAS.

\section{Dovepress}

The manuscript management system is completely online and includes a very quick and fair peer-review system, which is all easy to use. Visit http://www.dovepress.com/testimonials.php to read real quotes from published authors. 